Follow your nose:

Researchers turn

to disease-sniffing

animals to help with

diagnoses
Rearing to go:

Doctors transplant

feces to tackle gut

disease and pathogen

infections

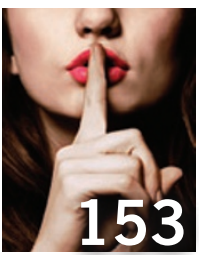

No more secrets:

Should state-

sponsored medical

research be more

transparent?

\title{
Are advance market commitments for drugs a real advance?
}

In December, health leaders in Nicaragua celebrated the integration of a vaccine against pneumococcal disease into their country's routine immunization program. It's no small achievement: pneumococcal disease kills more than 800,000 children under five years of age every year worldwide.

What's perhaps more notable is that the change was made possible by an advance market commitment (AMC), a first-of-itskind initiative devised by the GAVI Alliance in which donors provide funds to incentivize pharmaceutical companies to develop and distribute vaccines for the world's poorest nations.

In June 2009, the governments of Italy, Norway, Canada, Russia and the UK, along with the Bill \& Melinda Gates Foundation, committed $\$ 1.5$ billion to fund the pilot AMC. Last year, GlaxoSmithKline and Pfizer responded to the incentive, each committing to supply 30 million doses of their previously existing pneumococcal vaccines-GSK's Synflorix, which hit European markets in March 2009, and Pfizer's Prevenar-13, approved in the US in February 2010-for $\$ 3.50$ per dose. The two vaccines currently sell for over $\$ 70$ per injection in industrialized countries. Developing countries pay 15 cents of the $\$ 3.50$, with the remaining cost covered by the AMC.

"This is an incredibly great deal for the developing world," says Michael Kremer, an economist who studies vaccine markets at Harvard University in Cambridge, Massachusetts. The deal was so popular, in fact, that GAVI committed an additional $\$ 1.3$ billion to purchase the vaccines following an overwhelming demand for the product from developing countries, according to Jeffrey Rowland, director of media and communications for GAVI.

Over the next five years, the pneumococcal vaccines will be routinely administered in a total of 40 developing countries.

Vaccines typically reach the developing world 10 to 15 years after they become available in rich countries because the manufacturers first recoup their development costs from sales in industrialized countries. But Pfizer's pneumococcal vaccine, called Prevenar-13, hit US markets only ten months before the AMCfunded rollout in Nicaragua.

"What we're seeing right now has never been seen before," says Orin Levine, executive director of the International Vaccine Access Center at Johns Hopkins University in Baltimore. "There's no question that the AMC played a pivotal role in accelerating the vaccine's uptake and introduction." The vaccine will be distributed to seven more developing countries in the first half of 2011, with the goal of reaching over 40 developing countries by 2015 , says Rowland.

\section{Dollar for dollar}

Despite the fanfare around the pneumococcal vaccine rollout, some experts have expressed doubts about the AMC arrangement. Concerns about the cost-effectiveness of the AMC program surfaced in 2009, and today the expense of the program continues to escalate (Lancet 374, 1879-1880, 2009). GAVI's $\$ 1.3$ billion investment to complete the vaccine rollout by 2015 will not necessarily be easy to come by in the current economic environment.

Donald Light, a health policy researcher at the University of Medicine \& Dentistry of New Jersey in New Jersey and a longtime critic of the AMC approach, estimates the cost per child saved under the GAVI-sponsored $\mathrm{AMC}$ is $\$ 4,722$, whereas programs extending inexpensive vaccines for diseases such as polio, measles, and yellow fever to children who don't yet receive them would save more lives for less. "There are other, more holistic approaches that are much cheaper," says Light, such as multidrug package interventions for neglected tropical diseases that cost about 40 cents per person per year (PLoS Med. 2, e336, 2005). "The GAVI strategy emphasizing new vaccines is much more expensive and serves the interests of the main [pharmaceutical] companies," he adds.

A 2010 report from Oxfam International and Médecins Sans Frontières raises additional concerns, noting that the vaccines might have been purchased more cheaply by the regular, less-complicated UNICEF procedures for

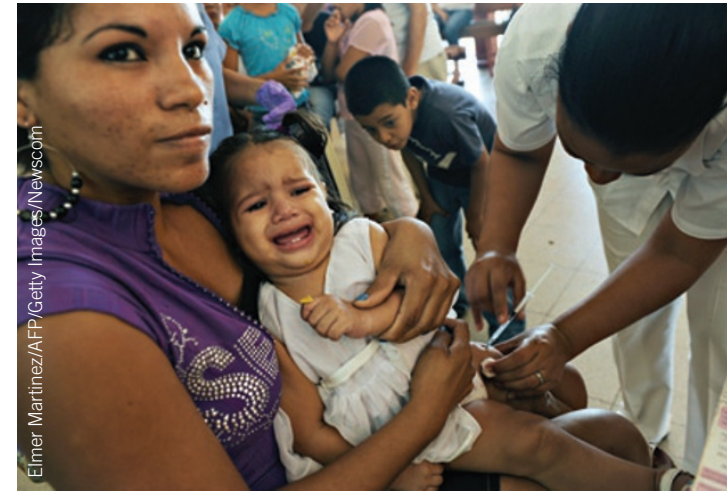

That's commitment: New drug pricing scheme.

buying vaccines for developing countries. The authors also point out that middleincome countries, such as Brazil and India, aren't eligible for GAVI support and therefore may not be able to afford the new vaccines. "The question remains whether this is an appropriate mechanism for stimulating development of new vaccines, as originally hoped," the authors write.

But some counter that, although the new, complex vaccines are costly compared to older vaccines, they would not otherwise be available so quickly to people in impoverished countries. "It's expensive, but it's not expensive relative to what it accomplishes," says Kremer. "It's saving a lot of lives for the money."

"It's too early to tell" if the program has been a complete success, adds Rowland. The pneumococcal AMC has yet to spark competition among pharmaceutical companies to bid for the supply contract, thus decreasing the price of the vaccine, as was originally intended. In addition, AMCs were originally designed to prompt manufacturers to discover and develop vaccines for neglected diseases for which no approved vaccines already exist, such as malaria. "I'd love to see [an AMC] with a more technologically distant target," says Kremer.

"This is a pilot. We're learning," says Rowland. There are no additional AMCs planned at the moment, he adds, but "everyone's asking."

Megan Scudellari 